\section{SP1-106 PREVALENCE OF OVERWEIGHT AND OBESITY AMONG NUTRITION FRESHMEN IN MEXICO: ACADEMIC YEAR COHORT STUDY}

doi:10.1136/jech.2011.142976n.83
F Jimenez-Guerra.* Universidad Veracruzana, Veracruz, Veracruz, Mexico

WHO predicts that $\sim 2.3$ billion adults will be overweight and more than 700 million will be obese by 2015 . Overweight and obesity have become major public health concerns in Mexico, reaching epidemic proportions among adults, adolescents and children in recent years. According to data from the most recent National Nutrition and Health Examination Survey (NNHES, 2006), Mexican youth have experienced a $7.7 \%$ increase in the prevalence rates of overweight and obesity (overall prevalence rate of $26.3 \%$ for both, NNHES, 2006). This study examined trends in overweight and obesity prevalence based on body mass index of the nutrition freshmen attending Veracruzana University from 2007 to 2009. A cross-sectional study was conducted with 271 nutrition freshmen attending classes during academic years 2007, 2008 and 2009, which represented $86 \%$ of overall sampling frame. BMI was grouped into 4 categories with the corresponding adolescent percentiles as recommended by the Centers for Disease Control and American Academy of Paediatrics and used to determine age- and sex-specific prevalence rates for overweight and obesity. Appropriate institutional ethics committee clearance and participants' informed consent were obtained. BMI-based nutritional classification showed an overall prevalence rate of $15.86 \%$ overweight and $3 \%$ obesity among freshmen for three academic years. The higher prevalence rates were $21 \%$ of overweight for 2007 and $4 \%$ of obesity for 2009 . This study highlights the higher prevalence rate of overweight and lower prevalence rate of obesity among University youth and suggests an observed trend comparable to the NNHES.

\section{SP1-107 RISK AND PROTECTION FACTORS FOR CHRONIC NON- COMMUNICABLE DISEASES BY TELEPHONE SURVEY, BRAZIL, 2009}

doi:10.1136/jech.2011.142976n.84

${ }^{1} \mathrm{~B}$ Iser, ${ }^{*}{ }^{2} \mathrm{R}$ Claro, ${ }^{2} \mathrm{E}$ Moura, ${ }^{1} \mathrm{D}$ Malta. ${ }^{1}$ National Coordination of Injury and NonCommunicable Disease Surveillance, Department of Health Analysis, Secretariat of Health Surveillance (SVS), Ministry of Health (MoH), Brasilia, Distrito Federal, Brazil; ${ }^{2}$ Center for Epidemiological Studies in Health and Nutrition, University of São Paulo, São Paulo, São Paulo, Brazil

Objective To describe the risk and protection factors for noncommunicable diseases with data from Surveillance System through telephone interviews (Vigitel) in 2009.

Methodology The prevalence of main risk and protection factors were estimated in adults ( $\geq 18$ years old), by telephone interviews in a probabilistic samples of population covered by landline telephones in Brazilian state capitals and federal district, stratified by sex, age and level of education.

Results Data from 54367 adults were collected. Risk factors like smoking, overweight, soft drinks and fat meat consumption and alcohol abuse were more prevalent in men, young adults and people with lower education level. Men were more active in leisure time and consume more beans than women. Poor self-rated health and self reported diagnosis of hypertension and dyslipidemia, however, were more prevalent in women. Vigitel 2009 results reinforce the trend in decrease of smoking and increase in overweight in Brazil.

Conclusion Telephone surveys are useful to provide timely information with less cost, making it an important tool to assess risk and protection factors for chronic diseases and health promotion actions.

\section{SP1-108 PERIODONTAL DISEASE AND ACUTE MYOCARDIAL INFARCTION: COMMUNITY CONTROLS VS HOSPITAL CONTROLS}

doi:10.1136/jech.2011.142976n.85

${ }^{1} \mathrm{I}$ Gomes-Filho, ${ }^{1}{ }^{1} \mathrm{~J}$ Coelho, ${ }^{1} \mathrm{~S}$ Seixas, ${ }^{1} \mathrm{~J}$ Passos, ${ }^{1} \mathrm{~A}$ Hintz, ${ }^{1} \mathrm{E}$ Cerqueira, ${ }^{2} \mathrm{M}$ Barreto. ${ }^{1}$ Feira de Santana State University, Feira de Santana, Bahia, Brazil; ${ }^{2}$ Bahia Federal University, Salavdor, Bahia, Brazil

Introduction Comparatively diverse groups have been used to study the association between periodontal infection and cardiovascular disease. However there is no consensus regarding the most appropriate control group to be used for this purpose.

Objective To compare the use of hospital controls vs community controls for the association between periodontal disease (PD) and acute myocardial infarction (AMI).

Method We outlined two case-control studies with 621 subjects. In the first, the Case Group was compared with 207 individuals in the Hospital Control Group (HC), and in the second with 207 individuals in the Community Control Group (CC). The Case Group was with diagnosis of first AMI event. Controls Groups were individuals with no history of previous AMI, matched by sex and age. The HC was selected from the same hospital as the Case Group, while the CC comprised of neighbours of the Case Group. The participants underwent a complete periodontal examination, were evaluated for lipids and glucose levels, anthropometric status, and responded to an interview. The ORs obtained were adjusted for confounder covariables and controlled by the co-effect modifying variables with a significance level of $5 \%$.

Results Among patients with PD the chance for AMI was higher among those without PD, CC (OR unadjusted $=1.57$ 95\% CI 0.98 to 2.52]) and for $\mathrm{HC}$ (OR unadjusted $=1.73$; $95 \% \mathrm{CI}$ [1.11 to 2.72$]$ ). After adjusting for age, sex, smoking, education level, occupation, glycaemic index and HDL cholesterol increased the chance for both groups with statistical significance: CC (OR adjusted $=1.89$; 95\% CI [1.11 to 3.28$]$ ) and HC (OR adjusted $=1.92 ; 95 \%$ CI $[1.14$ to 3.23$])$.

Conclusions The findings indicate that the PD is associated with AMI, independently of the control group.

\section{SP1-109 TRENDS IN PROSTATE CANCER INCIDENCE IN SETIF, ALGERIA BETWEEN 1987 AND 2007}

doi:10.1136/jech.2011.142976n.86

${ }^{1}$ Z Zoubida, ${ }^{*}{ }^{2} \mathrm{~A}$ Djemal, ${ }^{3} \mathrm{D} \mathrm{D}$ Aicha, ${ }^{1} \mathrm{M}$ Abbes, ${ }^{1} \mathrm{H} \mathrm{C}$ Mokhtar. ${ }^{1}$ Cancer registry of Setif, University hospital of Setif, Setif, Algeria; ${ }^{2}$ Department of Anatomopathology, University hospital of Setif, Setif, Algeria; ${ }^{3}$ Constantine Anti Cancer Center, University hospital of Constantine -Algeria, Constantine, Algeria

Introduction Prostate cancer is very common and while the incident rate is rising quickly, in many countries the mortality rate has started to fall Urological cancers comprise approximately one third of all cancers diagnosed in men worldwide, and prostate cancer is the commonest of these. The global burden of prostate cancer rose from 200000 new cases each year in 1975 to reach an estimated 700000 new cases in 2002. In Algeria, in 2002 prostate cancer was the eleventh most common cancer in men. Our study aimed for adjusting prostate cancer incidence trends over the longest period available 1987-2007 in Setif for the effect of age, sex, and period of diagnosis and the geographical distribution.

Material and Method Incidence datas were collected in the period 1987-2007 from the population-based cancer registry of Setif, the software used is the Can Reg 4.

Results In Setif, Prostate cancer ranked second among male population. Incidence was highest among men 80-82 age group 
(51.7\%) followed by men in 60-64 (30\%) and 75-79 (16.3\%) age group.

\begin{tabular}{lccc}
\hline & $\mathbf{1 9 8 7 - 1 9 8 9}$ & $\mathbf{1 9 9 3 - 1 9 9 7}$ & $\mathbf{2 0 0 2 - 2 0 0 7}$ \\
\hline Cases & $\mathbf{2 5}$ & 71 & 192 \\
$\%$ & 3.7 & 5.2 & 9.4 \\
ASR (100 000 males) & 2.9 & 4.3 & 8.2 \\
\hline
\end{tabular}

Age-adjusted incidence rate increased quickly from 2.9 per 100000 men to 8.2 per 100000 men in 2002-2007

Conclusion It represents $9.4 \%$ of all cancers reported in Setif. The results suggest that the prostate cancer ranked second among male population and the age-adjusted incidence rate increased quickly during these 2 decades.

\section{SP1-110 LUNG CANCER INCIDENCE AND TRENDS IN SETIF, ALGERIA BETWEEN 1986 AND 2008}

doi:10.1136/jech.2011.142976n.87

${ }^{1}$ Z Zoubida, ${ }^{2} \mathrm{M}$ Abdehak, ${ }^{1} \mathrm{~L}$ Slimane, ${ }^{3} \mathrm{~A}$ Djemal, ${ }^{1} \mathrm{M}$ Hamdi Cherif. ${ }^{1}$ Cancer registry of Setif, University hospital of Setif, Setif, Algeria; ${ }^{2}$ Department of pulmonary medicine, University hospital of Setif, Setif, Algeria; ${ }^{3}$ Anatomopathology Department, University hospital of Setif, Setif, Algeria

Background Lung cancer is the most frequent malignant neoplasm among men in most countries and represents the most important cause of cancer death worldwide, it accounts for an estimated 960000 new cases and 850000 deaths each year among men. In most populations, tobacco smoking accounts for $80 \%$ or more lung cancers. This study was designed to provide up-dated incidence figures for lung cancer in Setif at the period 1986-2008 adjusting for the effect of age, sex, and period of diagnosis and the geographical distribution of lung cancer at the national international level.

Material and Method Cancer registry represents a data source, the software used is the Can Reg 4 produced by the unit of descriptive epidemiology of the International Agency for Research on Cancer IARC, Lyon. France.

Results There were 188 cases of lung cancer registered during 2006-2008 representing 16.8\% of all cases among males. Incidence was highest among 80-85 age group with 122/100 000 followed by men in 85-90 with 45, 5/100000 for men. The median age at diagnosis was $65-69$ age group. The age-standardised rates increase from 11.7 to 23,8 per 100000 men these 2 decades.

Conclusion Between 1986 and 2008, the study showed a large change in the cancer burden both quantitatively and qualitatively. This evolution was due to demographic changes and an increase in the risk factors of cancer during this period 1986-2008.

\section{SP1-111 TRENDS IN BREAST CANCER INCIDENCE IN SETIF, ALGERIA BETWEEN 1987 AND 2007}

doi:10.1136/jech.2011.142976n.88

${ }^{1}$ Z Zoubida, ${ }^{*}$ A Djemal, ${ }^{3} \mathrm{D}$ D Aicha, ${ }^{1} \mathrm{~L}$ Slimane, ${ }^{1} \mathrm{M}$ Hamdi Cherif. ${ }^{1}$ Cancer registry of Setif, University Hospital of Setif, Setif, Algeria; ${ }^{2}$ Department of Anatomopathology, University Hospital of Setif, Setif, Algeria; ${ }^{3}$ Constantine Anti Cancer Center, University Hospital of Constantine -Algeria, Constantine, Algeria

Introduction Breast cancer is the most common cancer in women worldwide. It was estimated that 636000 incidents cases occurred in developed countries and 514000 in developing countries during 2002. Breast cancer is also the most important cause of neoplasic deaths among women; the estimated number of deaths in 2002 was 410000 worldwide. Our study aimed for adjusting breast cancer incidence trends over the longest period available 1987-2007 in Setif for the effect of age and period of diagnosis.

Material and Method Incidence datas were collected in the period 1987-2007 from the population-based cancer registry of Setif, the software used is the Can Reg 4.

Results Breast cancer ranked first among female population. Incidence was highest among women $30-55$ age group (63\%), the median age at diagnosis was $54-59$ age group.

\begin{tabular}{lccc}
\hline & $\mathbf{1 9 8 7 - 1 9 8 9}$ & $\mathbf{1 9 9 3 - 1 9 9 7}$ & $\mathbf{2 0 0 5 - 2 0 0 7}$ \\
\hline Cases & 187 & 317 & 224 \\
$\%$ & 10.3 & 22.2 & 21.1 \\
ASR (100 000 females) & 10.4 & 17.0 & 24.8
\end{tabular}

Age-adjusted incidence rate increased in this 2 decades from 10.4 per 100000 women in $1987-1989$ to 24.8 per 100000 women in 2005-2007.

Conclusion It is the most common cancer it represents $21,1 \%$ of all cancer sites reported in Setif cancer registry, more than $50 \%$ of new cases are the young women whose age is inferior at 40 years. It represents the first cause of mortality at women in Algeria it accounts 7000 deaths each year. The results suggest that the early detection should become a priority in Algeria.

\section{SP1-112 PREVALENCE OF HYPERTENSION AMONG BANGLADESHI ADULT POPULATION: A META-ANALYSIS}

doi:10.1136/jech.2011.142976n.89

${ }^{1} \mathrm{M}$ Zaman, ${ }^{1} \mathrm{~A}$ Taleb, ${ }^{1} \mathrm{~S}$ Rahman, ${ }^{1} \mathrm{~A}$ Acharyya, ${ }^{1} \mathrm{~F}$ A Islam, ${ }^{1} \mathrm{M}$ S A M Ahmed, ${ }^{*}$ ${ }^{2} \mathrm{M}$ Zaman. ${ }^{1}$ Bangladesh Institute of Health Sciences, Dhaka, Bangladesh; ${ }^{2}$ World Health Organization, Dhaka, Bangladesh

Background Hypertension is recognised as a major contributor to disease burden globally affecting $20 \%$ of adult population. More importantly it has become a significant problem in many developing countries experiencing epidemiological transition from communicable to non-communicable chronic diseases.

Objective The study was to determine the prevalence of hypertension among Bangladeshi adult population by meta-analysis.

Method In this meta-analysis the articles published during the period from 1995 to 2009 on the prevalence of hypertension among Bangladeshi adult population were identified by MEDLINE search included. We included those population based studies for this meta-analysis who clearly defined the diagnostic definition of hypertension and the age group ( $\geq 18$ years). We could locate thirteen articles, among them seven articles were excluded from the current analysis because they did not fulfil our selection criteria Then the prevalence of hypertension and their 95\% CIs $(\mathrm{p} \pm 1.96 \sqrt{\mathrm{pq}} / \mathrm{n})$ for the individual studies were calculated by using the data presented. Finally a pooled estimate was obtained from six studies.

Result The pooled estimates for the prevalence of hypertension in 6430 adults are $13.5 \%$ (with $95 \%$ CI $12.66 \%$ to $14.34 \%$ ).

Conclusion This meta-analysis clearly demonstrated that $13.5 \%$ adult population were at risk to develop cardiovascular and kidney diseases and this underscored the importance of screening of asymptomatic yet potentially harmful hypertensive disorders to combat the growing epidemic of Non-communicable Diseases.

Recommendation Large scale studies can be done including all the high risk population to represent the actual scenario of hypertension in Bangladeshi adult population. 